\title{
Sharing Knowledge Between the Peers of a Winery Network: The Case of Wine Routes in Northern Greece
}

\author{
Spyros Avdimiotis, Georgios Kokkinis \\ Alexander Technological Educational Institute, Thessaloniki, Greece \\ Eirini Kamenidou \\ Technological Educational Institute, Kavala, Greece
}

\begin{abstract}
It is widely accepted that effective knowledge management is an imperative factor for Destination Management Organizations and more especially Winery Networks. Although the importance of knowledge transfer has been acknowledged and thoroughly studied by scientists since the last quarter of the 20th century, tacit knowledge received less attention owing to the fact that it is very difficult to be codified and transferred. In this research paper we acknowledge the importance of knowledge transfer and we focus on the less attended and studied form of knowledge; the Tacit one, which according to many researchers is almost impossible to transfer. Towards this framework, we argue that tacit knowledge transfer could be facilitated through the use of customized rules and routines, based on Fuzzy Logic Rules. For that reason we contacted a research among wineries, in Northern Greece, examining the correlation extent among the factors that influence the knowledge transfer mechanism. The data extracted from the 37 interviews, well analyzed using the method of Factor Analysis and the most important subfactors were furthermore tested through multiple regression analysis method. The main findings of the research proved that fuzzy logic rules development will highly increase the levels of trust between the peers of the network.
\end{abstract}

Keywords: wine tourism, tacit knowledge transfer, Fuzzy Logic, rules development

\section{Introduction}

Knowledge management is a well-accepted concept in the contemporary tourism literature. In practice, the concept of knowledge transfer is increasingly discussed as the key factor in the process of innovation and competitiveness, while tourism activities continue to impact economically, socio-culturally and environmentally on destinations and the industry itself (Dwyer, 2005; Weaver \& Lawton, 2006).

On the contrary, the lack of appropriate knowledge management may be considered as one of the major barriers to adopt sustainability-related practices across the tourism industry (Baggio \& Cooper, 2008; Dwyer,

Spyros Avdimiotis, Ph.D., Lecturer, Alexander Technological Educational Institute.

Georgios Kokkinis, Ph.D., Assistant Professor, Alexander Technological Educational Institute.

Eirini Kamenidou, Ph.D., Associate Professor, Technological Educational Institute.

Correspondence concerning this article should be addressed to Spyros Avdimiotis, PO Box 141, Postal Code 57400, Thessakibiki, Greece. E-mail: rdoffice@gmail.com. 
2005; Weaver, 2006). Delving, furthermore, into the bibliography, Hislop, Newell, Scarborough, and Swan (1997) pointed out that knowledge articulation occurs in networks of organizations attempting to innovate and build upon knowledge. They identify two major types of networks: "Micro level” networks existing within the firm and "Macro level" inter-organizational networks. Focusing on the micro level networks, active knowledge transfer and distribution of tacit and explicit knowledge allows tourism firms to learn, respond and adjust flexibly and quickly to the constantly changing landscape of tourism, remaining competitive and, therefore, sustainable (Dwyer \& Edwards, 2008).

Towards this direction, Ahmed and Dwyer (2010) argue that effective knowledge management (acquisition, dissemination and responsiveness to knowledge) is an imperative factor for tourism organizations to attempt and achieve sustainability, acknowledging that knowledge is the backbone of innovation and competitiveness and the most valuable asset of businesses balance sheet, in general.

\section{Knowledge Transfer Factors}

Cummings and Teng (2003) argued that the precise definition of successful knowledge transfer is the ability to absorb the useful pieces of knowledge, adjust them to the network's needs, scopes and personnel skills and use them appropriately. According to Argote and Ingram (2000) and Nonaka (1994), transferred knowledge should be customized and thoroughly adjusted to the specific characteristics, tools and routines of the network's peers abilities. Knowledge could be considered as puzzle pieces which must be pieced together within the framework of a company. Knowledge receivers should have the ability to identify, pick and use the right pieces of knowledge in order to build the network's intellectual capital. This constant transformation and evolution of knowledge defines Nonaka's internalization of knowledge, during which the knowledge worker acquires the sense of ownership, commitment and use satisfaction, investing, at the same time, personal time, ideas and already acquired knowledge. The important question that needs to be answered is under which circumstances the knowledge worker will transfer his knowledge to the less experienced, enriching the actual knowledge capital contributing, at the same time, to the network's effort to innovate and apply sustainability measures.

Davenport and Prusak (1998) and Szulanski (2003) identified the factors of transfer stickiness, arguing that lack of psychological factors such as trust, state of relationship, willingness to communicate, adoption of responsibility and source reliability along with organizational structure factors, such as motivation, structure, leadership, information and communication technologies, could constrain the knowledge transfer process, weakening the organization intellectual capital.

\section{Tacit Knowledge Transfer in Winery Networks}

Fuller (1997), among others, expressed the opinion that both wine and wine tourism depend on the recognition of the destination. A wine network is defined in the market by a commercial label, which conveys the geographical identity and the origin of the wine. Quality wine promotes the image of the destination, contributing to the local economic development and to the promotion of the tourist product. Consequently, quality wine plays an important role/is instrumental in the creation of interest in the "wine routes" constituting the means it will be used to attract the customer, who is the visitor of a wine making region.

Wine tourism, as an alternative and sustainable form of tourism could be beneficial for the wineries and the 
destination in general, as well. In order to realize this, the active participation and fruitful co-operation of all network peers is required, while the backbone of this active and vital co-operation is based on the exchange of knowledge between the peers. Secrets of "how" and "when" must be shared, revealing an extensive and strong brand name of the destination. The critical point is the manner of this knowledge exchange will take place taking into consideration that this knowledge is mainly tacit, which according to the references is almost impossible to share.

The literature, among the plethora of definitions regarding knowledge management, has developed two major categories of knowledge: (1) Explicit; and (2) Tacit. Explicit knowledge is the kind of knowledge that is written and for that reason, easy to share, criticize, prove and transfer (Nonaka \& Takeuchi, 1991), while tacit knowledge, according to Davenport and Prusak (1998), cannot be found in written forms, being tightly bonded with emotions and experience. Michael Polanyi (1966) wrote in The Tacit Dimension, "we can know more than we can tell” (p. 4), arguing that tacit knowledge is subconscious, hence impossible to transfer (Choo \& Bontis, 2002). Aadne, Krogh, and Roos (1996) argued that the basis of knowledge is the tacit one, while Polanyi (1969) underline, that explicit knowledge rises from tacit which has been understood and codified. Inkpen and Dinur (1998), Cavusgil, Calantone, and Zhao (2003) proposed that knowledge is a concrete spectrum moving from tacit to explicitness and reversely, according to its content, while Boisot (1998) argues that the achievement of competitive advantage and innovation depends on the extent of transformation of tacit knowledge to explicit.

Haldin-Herrgard (2004) contacted a literature review discussing the tacit knowledge, from 1958 to 2002. The review resulted in 149 different synonyms (epitomes) used, among them the most frequent were, intuition, skills, values, behavior, insight, mental models, practical intelligence, know-how, etc.. All these synonyms and phrases were used to underline that tacit knowledge management is based on abstract meanings, practices and competences, the common approach and understanding of which will reverse in a significant extent the chaotic conditions of communication between the knowledge workers.

Knowledge management and knowledge sharing has been the subject of many scientific researches during the last few decades, but, as Shaw and Williams argued in 2009, in tourism, it is still an emerging agenda. Tourism, as one of the most important pillars of global development, with massive social, environmental and economical impacts, is a field where knowledge is the cornerstone of flexible management, constantly trying to anticipate the needs of the guests. This whole dynamic structure of experience building is widely based on those who can combine tacit knowledge and experience with explicit (written) knowledge that can be easily acquired in learning organizations.

\section{Fuzzy Logic}

The foundations of the Fuzzy Logic theory, were developed in 1965 by Lotfi Zadeh, questioning the sufficiency of the Boolean Logic of true or false and introducing the notion of partially true or partially false, covering the "middle grey" zones in the process of problem-solving or decision-making. This binary method of evaluating a fact or a state is based on the Aristotle's logic, using only the two arithmetic digits of I (true) and $\mathrm{O}$ (false), dissuading the recognition and the evaluation of all intermediate values between these limits. On the other hand, Fuzzy Logic takes into account all possible ranging values, offering the possibility of simultaneous evaluation of the ranging states between the I/O limits, corresponding to a degree, or a part of truth. The 
theoretical structure of Fuzzy Logic facilitates a more "natural" manner of data-processing, offering at the same time the possibility to the decision maker to adjust the evaluation rules to the specific characteristics of internal and external environment. In other words, the Fuzzy Logic's main concern and scope is to represent, manipulate and draw inferences from statements that are imprecise, vague or fuzzy.

For example:

- The description of a human characteristic as healthy;

- The classification of people by age such as old;

- The classification of certain objects as large;

- A rule for driving such as "if an obstacle is close, then brake immediately".

In the sentences above, terms such as healthy, old, large, close, immediately, are fuzzy in the sense that they cannot be sharply and commonly defined. However, as humans, we do make sense of this kind of information and use during all the levels of the decision-making process, by classifying the degree of being healthy, old, large etc., in subsets, in a given set of people under given circumstances or variables (Nguyen-Walker, 2002). These sets are characterized by a membership degree function which maps the percentage of truth based on personal and, therefore, subjective criteria into the interval [0-1]. In order to confront the problem of diverse uncommon and subjective classification of values into specific datasets, the tool of Fuzzy rules was developed to represent and exploit this algorithm of human thinking. Fuzzy Logic with fuzzy rules has the potential to add subjective reasoning capabilities to decision-making processes by using verbal terms and mapping the knowledge-mainly the tacit—of humans. Fuzzy rules have two distinctive parts, the IF (hypothesis) and THEN (inference) part, i.e., "If the room gets hotter, then spin the fan blades faster", where the temperature of the room and speed of fan blades are both imprecisely defined quantities and hotter and faster are both fuzzy terms. Defining these terms by using Fuzzy Logic, we could develop (exponential) rules such as "if the room gets a temperature more than 26 degrees, then you should increase the blades spin speed by 10\%”.

Fuzzy Logic systems had been widely used in Multi-Criteria decision-making Processes, in control development systems, regarding aircrafts, vehicles, air-conditioning systems and so on, quite successfully during the last decade. The aim of this paper is to examine whether the development of rules based on Fuzzy Logic could effectively affect the knowledge transfer mechanism in a network, taking into account that the whole process of knowledge transfer within the sector seems to be linear, unstable and complicated.

\section{Business Rule Set Up}

Focusing on the business rule set up, Cohen (1995) considers that a rule is a relationship that allows individuals to fulfill an action under the appropriate conditions. The process of responding to these conditions can be either automatic or deliberate and conscious. On the same issue, Hodgson (1994-1995), defines rules as patterns of thought or behavior, which can (or cannot) be adopted, either consciously or subconsciously, by individuals. Hodgson shows that the main characteristic of rules can be defined by the logical structure of condition and action: in circumstances $\mathrm{X}$, do Y. The formal rules' contribution to the organization is to specify tasks and decision competencies for organization members, regulating hierarchical relationships and work procedures. According to Winter (1995b), rules do not define how individuals or teams should do their work, or even how to improve it, but to impose the appropriate normative framework regulating organizational behavior 
facing numerous organizational constraints. The setup of Fuzzy Logic rules in the organization, on the other hand, not only contributes to the overall behavior regulation, but it provides the basis for effective and operative co-operation between individuals and teams, increasing the volume of communication and trust among them, by giving a mathematical value to common subjective notions, leaving no space for misapprehensions, disputes and misunderstandings. According to Gilbert and Cordey-Hayes (1996), and Nonaka (1994), tacit knowledge can be developed or assimilated into core routines of the organizations. Therefore, the establishment of a Fuzzy Logic normative framework can play a critical role in articulating, amplifying and transferring new knowledge which can be created by the interrelation between structural behavior and routines of individuals and teams.

While the establishment of Fuzzy Logic rules in industrial production and multi criteria decision-making process has been a rapidly emerging issue, in tourism it is still in the state of mitosis, mostly owing to its particular characteristics.

According to Lotfi Zadeh (1965) there are five basic conditions, where the methodology of Fuzzy Logic is considered as an essential and valuable tool: (1) The difficulty to create a structural model of the functional activities; (2) The significant role of tacit workers who tend to refuse transferring their acquired knowledge to the less experienced ones, weakening the knowledge capital of the organization; (3) the constant and complex flows of data and information into the system; (4) The use of observation as a criterion for the location of contingent problems; and (5) the general fuzziness of the used notions that determine the system. Tourism is fulfilling all the above conditions, being a quite sophisticated, global and interdisciplinary phenomenon, depending almost exclusively on the human factor, with massively complex flow of data and information among stakeholders. At the same time, the gain of experience and the enrichment of emotions that, according to Christou (2004), constitute the overall outcome of the tourism services, are also a fuzzy notion, determining and proving at the same time, that Fuzzy Logic could be a key factor for the acquisition, adjustment and transfer of knowledge, within the tourism system.

\section{The Research Model}

The primary aim of the paper is to investigate the stimulation extent of tacit knowledge transfer and dissemination among network peers, where the guesses, hunches, imaginings and passion-as forms and expressions of tacit knowledge - could be converted to explicit knowledge. In order to achieve this, we use the tool of Fuzzy Logic, combined with the development of a certain dynamic set of rules, built and based on democratic management structures, where constant dialogue is taking place, starting from the top management to the front line personnel. The hypothesis on which the research was based is "the development of rules based on Fuzzy Logic is positively correlated with tacit knowledge transfer, within the organization”.

To prove the accuracy of the hypothesis, a model was developed (see Figure 1) in which the most important factors of knowledge development, with the new factor of the development of sets of rules based on Fuzzy Logic, were correlated. There were also correlations of this factor with the absorptive capacity and the overall effectiveness of knowledge transfer, as defined by Szulanski (2003).

In more detail, the factors chosen to be correlated with the development of Fuzzy Logic rules, towards knowledge transfer are: (1) Trust; (2) Communication; (3) Motivation; (4) Leadership; (5) Organizational structure; (6) Perceived use of knowledge; (7) ICTs; (8) Already acquired knowledge; (9) Networking; and (10) 
Knowledge codification. For each factor a sub-hypothesis was built, aiming at the research analysis of the main hypothesis, regarding the contribution of fuzzy logic based rules to tacit knowledge transfer.

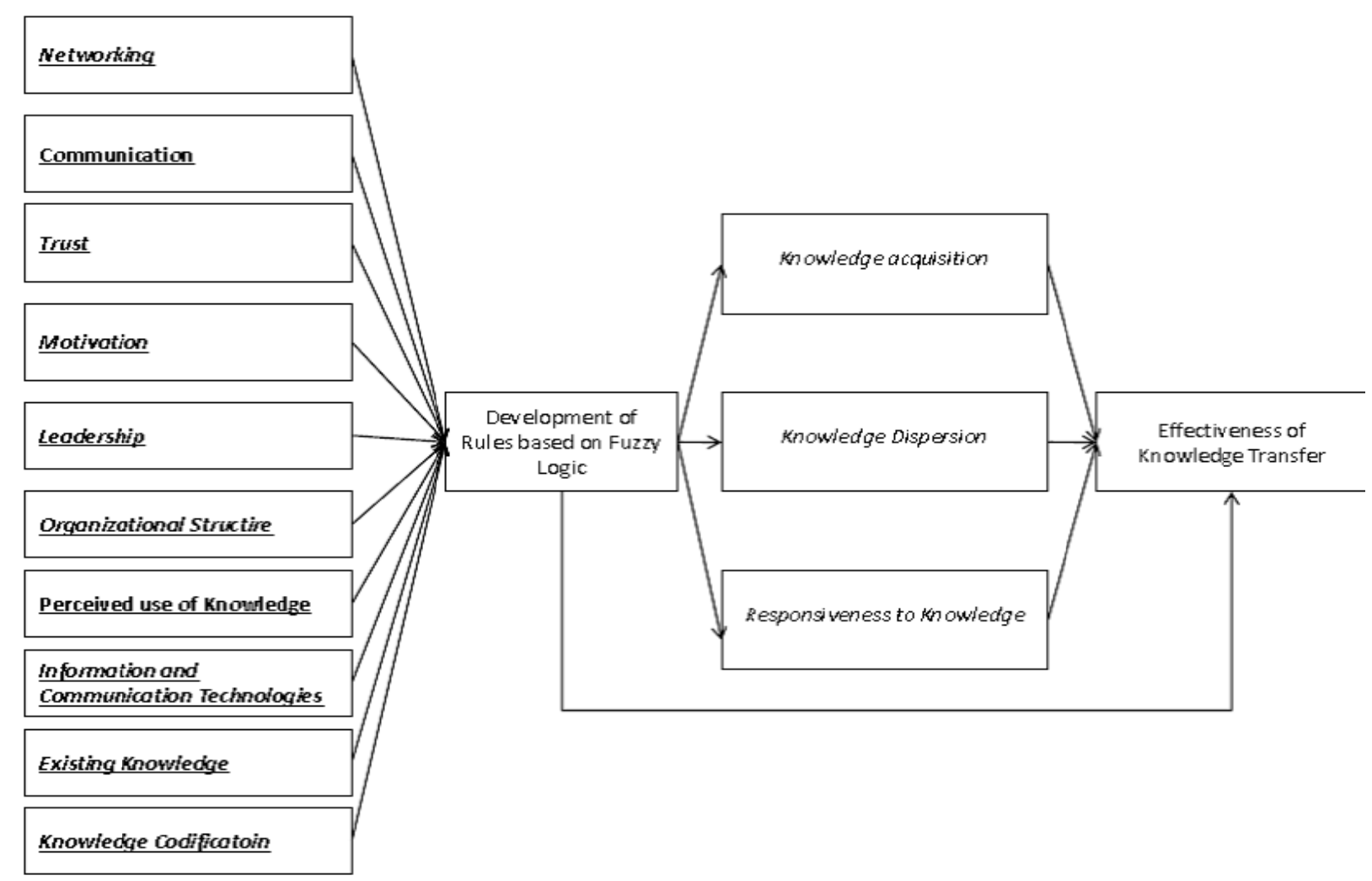

Figure 1. The overall hypothesis.

\section{Research Method}

For research purposes, a basic scientific model was developed, in which the most important factors of knowledge development, along with the new factor of fuzzy logic based rules (FLbR), were correlated. There were also correlations of FLbR with the absorptive capacity and the overall effectiveness of knowledge transfer, as it was defined by Szulanski (2005). The primary research was conducted during the second half of 2010, realizing 78 semi-structured interviews in 37 wineries, in Northern Greece. For the acquired data, a description analysis was conducted. The reliability of the questionnaire was estimated, by the use of internal consistency. The factor $\alpha$ (coefficient alpha) is a useful tool for the estimation of the internal consistency. The Cronbach $\alpha$ factor was used for that reason. The highest scored variables were used for further statistical processing, using the method of factor analysis, a test that explores relationships among data. Factor analysis also explores which variables in a data set are most related to each other. In other words, it is a form of multivariable analysis that takes a large number of factors and variables aiming to identify a minimum number of factors that explain possible interrelations among them, by reducing the number of variables and detecting structure in the relationships among the elements in the analysis.

Regarding the correlations, the Pearson index was used showing the volume and the degree of correlations between the variables. For the multiple regression analysis, an equation was developed, resulting to the 
determination of the most important factors of successful knowledge transfer in a winery network, using the tool of development of Fuzzy Logic rules, in the winery.

The structure of the questionnaire was based on reference items determining each independent variable of effective knowledge transfer as shown in Table 1.

Table 1

References of Items per Variable

Knowledge transfer factors item reference source

\begin{tabular}{l|l}
\hline Communication & 3 items based on Becerra and Gupta (2003), Hansen, Nohria, and Tierney (1999)
\end{tabular}

\begin{tabular}{|l|l|}
\hline Trust & 5 items based on Levin and Cross (2004) \\
\hline Motivation & 5 items based on Bock, Zmud, Kim and Lee, (2005), Brachos, Kostopoulos, Soderquist, and Prastacos \\
\hline
\end{tabular}

\begin{tabular}{l|l}
\hline Motivation & $\begin{array}{l}5 \text { items based on Bock, Zmud, Kim and } \\
\text { (2007), Cummings and Teng (2003) }\end{array}$ \\
\hline
\end{tabular}

Leadership $\quad 5$ items based on Christensen (2002), Levinson, Kita, Haun and Rasch (2002), Lovelace, Shapiro and

Weingart (2001), Sveiby (1996), Vera and Crossan (2004)

Organizational Structure 3 items based on Birkinshaw et al. (2002)

\begin{tabular}{|l|l|}
\hline Perceived use of & 7 items based on Hansen, Nohria and Tierney (1999), Levin and Cross (2004), Szulanski (1996) \\
\hline
\end{tabular}

\begin{tabular}{l|l} 
Knowledge & 7 items based on Papoutsakis (2006), Tippins and Sohi (2003) \\
\hline ICT &
\end{tabular}

\begin{tabular}{l|l} 
ICT & 7 items based on Papoutsakis (2006), Tippins and Sohi (2003) \\
\hline
\end{tabular}

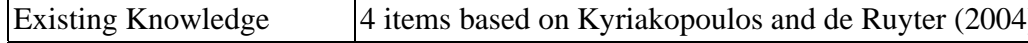

\begin{tabular}{l|l}
\hline $\begin{array}{l}\text { Codification of } \\
\text { Knowledge }\end{array}$ & 5 items based on Reagans and McEvilly (2003) \\
\hline
\end{tabular}

\begin{tabular}{|l|l}
\hline Business Network & Camisón and Forés (2007), Mowery, Oxley, and Silverman (1996), Reagans and McEvilly (2003)
\end{tabular}

12 items based on Bennet and Gabriel (1999), Cohen and Levinthal (1990), Galvin (1996), Kohli and

Knowledge Acquisition $\quad$ Jaworski (1990), Lane and Lubatkin (1998), Nonaka and Takeuchi (1995), Sinkula (1997), Szulanski (1996), Zahra and George (2002)

Knowledge Dissemination 9 items based on Bennet and Gabriel (1999), Galvin (1996), Kohli and Jaworski (1990), Lane and Lubatkin (1998), Nonaka and Takeuchi (1995), Zahra and George (2002)

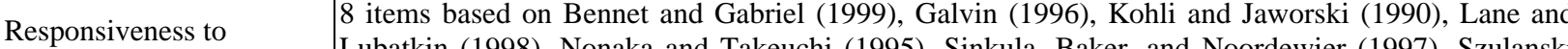
Knowledge $\quad$ Lubatkin (1998), Nonaka and Takeuchi (1995), Sinkula, Baker, and Noordewier (1997), Szulanski

9 9 items based on Pierce, Kostova, and Dirks (2002), Szulanski (2003)

\section{Research Findings}

The aim of the present research has been to clarify what Fuzzy Logic is, how this can be formulated into rules and what their contribution is to the operation of network peers. According to the main results of the research, with the development of rules based on Fuzzy Logic, there is an improvement mainly in trust, communication, leadership effectiveness, peers' motivation, and the already existing accumulated knowledge. Moreover, the perceived use of information is more effective, while the efficiency of the administrative structure is increased. More specifically, the trust is significantly influenced, mainly because the rules of Fuzzy Logic improve personal competence and increase the peers' professionalism, a fact that finally creates a strong climate of trust within the winery network environment.

In addition, communication becomes more effective, as messages transmitted among members are more well-defined and clear. This improvement is observed not only on departmental level but also on the entirety of the business.

Motivation is also enhanced as the targets are well-defined and clear and the efficiency rating of personnel is less subjective and more trustworthy. Moreover, the realization of the goals as these are formed by the rules of 
Fuzzy Logic, is a prize, both financial and moral, for peers, while, additionally, motives for collaboration and exchange of expertise are developed owing to better coordination and increased teamwork in the network.

The development of rules significantly helps in better understanding knowledge (perceived usefulness) and information. These are more effectively utilized and much more easily transferred from the peers to third parties.

With the development of Fuzzy Logic rules, the administrative structure seems to become more democratic and open, ways to improve labor efficiency are promoted, the efficiency rating of personnel is improved, innovatory action is encouraged, while the possibility of decision-making in common among members is also increased. Of course, it must be pointed out that not any change and adaptation of rules brings positive results in case the flexibility and effectiveness of administrative structure are not increased.

Moreover, with the development of Fuzzy Logic rules, the business leadership team has a clearer role to play and if it cooperates with the employees it is more democratic and the decisions and measures it takes can be rationalized. The commitment of employees and departments in achieving the goals of the network is greatly facilitated, the collective and personal responsibilities are successfully clarified to a great extent, individual initiative and innovation are encouraged as well as the spirit of teamwork and cooperation within the winery network.

The already existing accumulated knowledge is significantly fortified, as with the development of rules innovation can be enhanced, nevertheless, members with rich experience are reluctant to share their expertise, mainly on practical matters, with members of the lower ranks of the hierarchy. On the contrary, knowledge is more easily shared among member with less experience.

Concerning the three factors, i.e., codification, networking and use of information and communication technologies, the results are more negative than positive.

More specifically, networking with other enterprises does not seem to be influenced almost to any extent from the development of rules, since neither the assimilation of knowledge received from external entities, nor the transmission to them are favored. Only cooperation and networking within the firm and among departments are encouraged.

The codification of knowledge through rules of Fuzzy Logic is feasible, since it is possible for automatic processes of control of the effectiveness of the employees' performance to be applied. On the other hand, the rules neither contribute to the precise job-description of employees, nor to the creation of a well-documented guide to solving the problems arising in the network.

Finally, the communication and information technologies can support the development and dissemination of the rules, through the creation of an electronic data base to be used in solving problems that may arise in future in the winery networks, to contribute to the better coordination of local wineries and, more generally, if the right facilities exist, then the rules can be transmitted to the winery network members of the firm with the use of electronic computers. Yet, with only the rules as a base it would not be possible to develop a means sufficient to check members of the winery network; nor this can fully describe the work content of local distilleries as well as the limits of their responsibilities. Finally, the executives are worried and intensely doubt about the final usefulness of such an electronic guide in the administration and the network peers, as well as if it is possible to disseminate it within the wineries. The main reason for such reservations is the fact that the rules are extremely dynamic and change their content and structure very quickly. 
Besides, the acquisition of knowledge is facilitated with the development of the rules of Fuzzy Logic, mainly because the detection of the appropriate source of information is easier and the creation of a common base of perception of this information is enhanced. Moreover, to the appropriate and effective reception of knowledge contributes the fact that through the rules members of the network communicate better and more often among themselves both at a professional as well as at a social level.

In addition to the acquisition of knowledge, the rules of Fuzzy Logic facilitate the dissemination of information as they create conditions of effective communication and elevated confidence. Nevertheless, it must be noted that the rules do not induce to more effective and substantial use of the facilities and means of information, a fact that makes difficult the dissemination of knowledge.

Regarding the response to knowledge, the development of rules of Fuzzy Logic contributes mainly to more immediate response and adaptation to new knowledge, as well as to the localization and the immediate response to complaints or change in the peer's attitude that may arise. Moreover, the immediate response in managing crises that may arise, is achieved, and the existing knowledge is used in a very efficient way.

Finally, with the development of rules of Fuzzy Logic, the knowledge transfer factor is greatly facilitated, mainly because the rules help to solve problems that may arise during the transmission of information, facilitate decision-making, contribute to better understanding of demands and competencies, as well as the limits of their actions, lead to the network members, feeling more competent and confident to deal with potential problems, they improve the climate of cooperation and trust in the network, assist to better communication, contribute to the processes of evaluation of the present and new knowledge to be followed and, moreover, help in bolstering the importance of lifelong learning.

Referring to the main factors under investigation, more specifically: acquisition of, dissemination of and response to knowledge, the results have shown that these are influenced mainly by the degree of improvement of personal competence of employees, whether there is trust among members, by the degree in which communication is improved among departments, as well as to whether the content of knowledge and the way this is passed to third parties as a result of the application of rules of Fuzzy Logic.

The credibility of the questionnaire was checked using the coefficient alpha $(\alpha)$, to calculate the internal coherence of the scale. The Cronbach $\alpha$ delivers clear results of the variables used, as shown in the following table.

For the factors: (1) Trust; (2) Communication; (3) Perceived use of knowledge; and (4) Dissemination, which achieved coherence averaged over 0.70 , there is high internal coherence and credibility, therefore these factors will be further more statistically analyzed using the factor analysis method, which demonstrates the validity of the construction. More specifically, the factor of TRUST represents a high value of Keiser Meyer Olkin index (0.861) at level of importance of $1 \%$, proving that the coherence of data is very high. Therefore, the variables of "personal pertinence", "professionalism” and "trust culture” were created.

The factor of communication, has also achieved high value regarding the Keiser Meyer Olkin index (0.828) at level of importance of $1 \%$. The variables formulated after the process, were "overall communication improvement" and "departmental communication improvement".

The factor of perceived use of knowledge had Keiser Meyer Olkin index value at 0.762 . According to the factor analysis process, the variables formulated were "understanding and transfer of knowledge" and 
"knowledge usefulness".

The factor of knowledge dissemination had Keiser Meyer Olkin value of 0.730 determining the creation of the factors "trust and communication" and "infrastructure and culture of knowledge transfer".

Figure 2 represents the strong correlations found, between the aforementioned independent variables and the depended variables of "acquisition”, “dissemination”, "responsiveness” and "knowledge transfer effectiveness”.

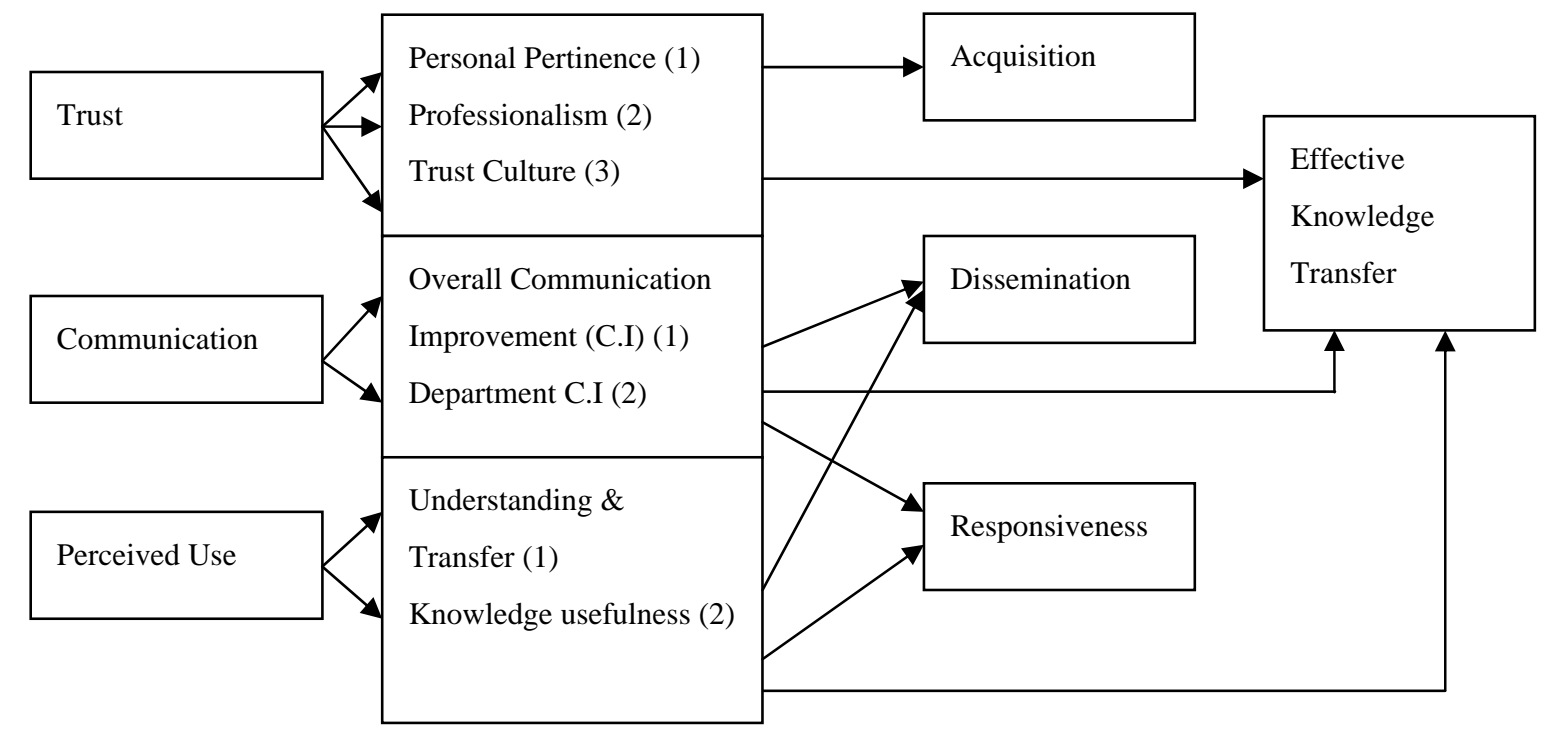

Figure 2. Factor correlations.

The process indicated a strong correlation between the depended variables of "acquisition”, "dissemination”, "responsiveness" and "effective knowledge transfer" and the independent variables (as the result of factor analysis) "personal pertinence", "professionalism”, “departmental communication improvement" and "understanding and transfer of knowledge”, with the Pearson indicator varying from 0.312 to 0.424 .

Proceeding to the multiple regression analysis, an equation was formulated in order to verify the most influential factor of tacit knowledge transfer.

$$
\begin{aligned}
& \text { Eff_kn=bo }+b 1 * i n d \_c o m \_e n c e+b 2 * \text { prof_lism }+b 3 * t r u s t \_s e \_c u l+b 4 * t o t a l \_i m p r \_c o m m+b 5 * \\
& \text { com_tion_m+b6*compr_trans_kn+b6*it_use_ex }
\end{aligned}
$$

where $E f f k n$ is a dependent (false) variable which was extracted from the mean values scored from questions regarding the effective knowledge transfer, ind_com_ence independent (false) variable extracted from the mean values scored from questions regarding that factor "personal pertinence”, prof_lism independent (false) variable extracted from the mean values scored from questions regarding that factor "professionalism, trust_se_cul independent variable expressing the degree trust culture is created as a result of Fuzzy Logic Rules development, total_impr_comm independent (false) variable extracted from the mean values scored from questions regarding that factor "overall communication improvement", com_tion_m independent variable expressing the degree of overall communication improvement as a result of Fuzzy Logic Rules development, compr_trans_kn independent (false) variable extracted from the mean values scored from questions regarding that factor "understanding and knowledge transfer", it_use_ex independent variable expressing the degree of knowledge usefulness as a result of Fuzzy Logic rules development. 
Table 2 demonstrates the first example of regression between the independent and dependent variables.

Table 2

Regression Analysis

\begin{tabular}{llll}
\hline & 1 & 2 & 3 \\
\hline & $0.000 /(5.364)$ & $0.000 /(26.728)$ & $0.000 /(28.600)$ \\
1. Personal pertinence & $0.027 * /(2.234)$ & $0.052 /(1.960)$ & $0.000 /(5.132)$ \\
2. Professionalism & $0.493 /(0.688)$ & & \\
3. Trust culture & $0.941 /(0.074)$ & & \\
4. Overall communication improvement & $0.996 /(0.005)$ & & \\
5. Departmental communication improvement & $0.087 /(-1.725)$ & & \\
6. Understanding and knowledge transfer & $0.018 * /(2.401)$ & $0.066 * /(1.859)$ \\
7. Knowledge usefulness & $-0.774 /(-0.288)$ & & \\
\hline
\end{tabular}

The important variables in 5\% level of importance were: (1) Personal pertinence; and (2) Understanding and knowledge transfer. In the second model of regression, the variable "understanding and knowledge transfer" was statistically insignificant ( $p=0.066, p>0.05$ ). In the 3rd model of regression, only the statistically significant variable of "personal pertinence" was included.

Regarding the overall evaluation of econometric models and from what has been written before, it becomes obvious that the rules of Fuzzy Logic contribute to a great degree to the improvement of personal competence of employees, as well as to the enhancement of trust among peers, factors that finally influence and define the degree of effectiveness of the transfer of knowledge and information.

\section{Conclusion}

Malhorta (2002, p. 77) argues "The best information environments will take advantage of the ability of IT to overcome geography but will also acknowledge that the highest bandwidth network of all is found between the water fountain and the coffee machine” meaning that the assignees and the face to face meeting are by far the most important channels for generating, reusing and transferring knowledge. Santoro and Bierly (2006) support the argument that knowledge transfer is an inherently social processes of the workplace in many ways, not easy to formalize, codify, visualize and express, highly dependent upon interactions among team members (Joshi, Sarker, \& Sarker, 2007). Tacit knowledge is considered as the "body of the iceberg" of the intellectual capital, which, according to Druker (1993), is the most valuable asset of the organization. Hence, the initial scientific question is the exploitation manner of tacit knowledge, acknowledging the fact that the key factors of tacit knowledge transfer process seem to be mostly psychographic. The intangibility of tacit knowledge must be handled with also intangible factors, such as communication, trust, perception, etc.. Researchers such as Malhorta, Drucker Polayni, Nonaka, Szulanski, Konno, Darroch and many others, agree that tacit knowledge depends on the extent of communication, trust, ability to express and culture. This research paper argues that the development of rules based on Fuzzy Logic could strongly improve communication and individual pertinence, enhancing the level of trust, knowing that trust is a key factor of tacit knowledge transfer.

\section{References}

Aadne, J., von Krogh, G., \& Roos, J. (1996). Representationism: The traditional approach to cooperative strategies. In G. von Krogh, \& J. Roos (Eds.), Managing knowledge: Perspectives on cooperation and competition (pp. 9-31). London: Sage. 
Ahmed, E., \& Dwyer, L. (2010). The role of knowledge-based networks in sustainable tourism development-A conceptual framework. In BESTEN Think Tank X: Networking for Sustainable Tourism.

Argote, L., \& Ingram, P. (2000). Knowledge transfer: A basis for competitive advantage in firms. Organizational Behavior and Human Decision Processes, 82(1), 150-169.

Baggio, R., \& Cooper, C. (2008). Knowledge management and transfer in tourism: An Italian case. IASK-Advances in Tourism Research 2008, Aveiro, Portugal, May 26-28, 2008. Aveiro, ATR 2008, 44-53.

Becerra, M., \& Gupta, A. (2003). Perceived trustworthiness within the organization: The moderating impact of communication frequency on trustor and trustee effects. Organization science, 14(1), 32-44.

Bennett, R., \& Gabriel, H. (1999). Organisational factors and knowledge management within large marketing departments: An empirical study. Journal of Knowledge Management, 3(3), 212-225.

Birkinshaw, J., Nobel, R., \& Ridderstråle, J. (2002). Knowledge as a contingency variable: Do the characteristics of knowledge predict organizational structure? Organization Science, 13(3), 274-289.

Bock, G., Zmud, R., Kim, Y., \& Lee, J. (2005). Behavioral intention formation knowledge sharing: Examining roles of extrinsic motivators, social-psychological forces, and organizational climate. MIS Quarterly, 29(1), 87-111.

Boisot, M. (1998). Knowledge assets: Securing competitive advantage in the information economy. New York: Oxford University Press.

Brachos, D., Kostopoulos, K., Soderquist, K., \& Prastacos, G. (2007). Knowledge effectiveness, social context and innovation. Journal of Knowledge Management, 11(5), 31-44.

Camisón, C., \& Forés, B. (2011). Knowledge creation and absorptive capacity: The effect of intra-district shared competences. Scandinavian Journal of Management, 27(1), 66-86.

Cavusgil, S., Calantone, R., \& Zhao, Y. (2003). Tacit knowledge transfer and firm innovation capability. Journal of Business \& Industrial Marketing, 18(1), 6-21.

Choo, C., \& Bontis, N. (2002). The strategic management of intellectual capital and organizational knowledge. New York: Oxford University Press.

Christensen, C. (2003). Beyond the innovator's dilemma. Harvard Business Publishing Newsletters, 1(1), 1-4.

Christou, E. (2004). The impact of trust on brand loyalty: Evidence from the hospitality industry. Tourist Scientific Review, 1(1), 1-4.

Cohen, M. (1995). Individual learning and organizational routine. In M. Cohen, \& L. Sproull (Eds.), Organizational learning (pp. 9-31). London: Sage.

Cooper, C. (2006). Knowledge management and tourism. Annals of Tourism Research, 33(1), 47-64.

Cummings, J., \& Teng, B. (2003). Transferring R\&D knowledge: The key factors affecting knowledge transfer success. Journal of Engineering and Technology Management, 20(1-2), 39-68.

Davenport, T., \& Prusak, L. (1998). Working knowledge: How organizations manage what they know. Boston: Harvard Business School Press.

Drucker, P. F. (1993). Post-capitalist society. New York: Harper Collins.

Dwyer, L. (2005). Relevance of Triple Bottom Line reporting to sustainable tourism: A scoping study. Tourism Review International, 9(1), 79-94.

Dwyer, L., \& Edwards, D. (2009). Tourism product and service innovation to avoid "strategic drift”. International Journal of Tourism Research, 11(4), 321-335.

Frazier, J. (1997). Sustainable development: Modern elixir or sack dress? Environmental Conservation, 24(2), 182-193.

Galvin, R. (1996). Managing knowledge towards wisdom. European Management Journal, 14(4), 374-378.

Gilbert, M., \& Cordey-Hayes, M. (1996). Understanding the process of knowledge transfer to achieve successful technological innovation. Technovation, 16(6), 301-312.

Haldin-Herrgard, T. (2000). Difficulties in diffusion of tacit knowledge in organizations. Journal of Intellectual Capital, 1(4), 357-365.

Hansen, M., Nohria, N., \& Tierney, T. (1999). What’s your strategy for managing knowledge? Harvard Business Review, 77(2), 106-116.

Hislop, D., Newell, S., Scarborough, H., \& Swan, J. (1997). Innovation and networks: Linking diffusion and implementation. International Journal of Innovation Management, 1(4), 427-448.

Hodgson, G. (1995). The necessity of habits and rules. University of Cambridge. Research Papers in Management Studies, No. 5.

Inkpen, A., \& Dinur, A. (1998). Knowledge management processes and international joint ventures. Organization Science, 9(4), 454-468. 
Joshi, K., Sarker, S., \& Sarker, S. (2007). Knowledge transfer among face-to-face information systems development team members. Decision Support Systems, 43(2), 322-335.

Kohli, A., \& Jaworski, B. (1990). Market orientation: The construct, research propositions, and managerial implications. The Journal of Marketing, 54(2), 1-18.

Kyriakopoulos, K., \& De Ruyter, K. (2004). Knowledge stocks and information flows in new product development. Journal of Management Studies, 41(8), 1469-1498.

Lane, P., \& Lubatkin, M. (1998). Relative absorptive capacity and interorganizational learning. Strategic Management Journal, 19(5), 461-477.

Levin, D., \& Cross, R. (2004). The Strength of weak ties you can trust: The mediating role of trust in effective knowledge transfer. Management Science, 50(11), 1477-1490.

Levinson, S., Kita, S., Haun, D., \& Rasch, B. (2002). Returning the tables: Language affects spatial reasoning. Cognition, 84(2), 155-188.

Lovelace, L., Shapiro, D., \& Weingart, L. (2001). Maximizing cross-functional new product team's innovativeness and constraint adherence: A conflict communications perspective. The Academy of Management Journal, 44(4), 779-793.

MacLellan, L. (1997). The tourism and the environment debate: From idealism to cynicism. In M. Foley, J. Lennon, \& G. Maxwell (Eds.), Hospitality, tourism and leisure management: Issues in strategy and culture (pp. 177-194). London: Cassel.

Malhotra, Y. (2002). Why knowledge management system fail? Enablers and constraints of knowledge management in human enterprises. In C. Holsapple (Ed.), Handbook on knowledge management (pp. 577-599). Heidelberg: Springer.

Mowforth, M., \& Munt, I. (1998). Tourism and sustainability: New tourism in the third world. London: Routledge.

Mowery, D., Oxley, J., \& Silverman, B. (1996). Strategic alliances and interfirm knowledge transfer. Strategic Management Journal, 17(Winter special issue), 77-91.

Nonaka, I. (1991). The knowledge-creating company. Harvard Business Review, 69(6), 96-104.

Nonaka, I. (1994). A dynamic theory of organizational knowledge creation. Organization Science, 5(1), 14-37.

Nonaka, I., \& Konno, N. (1998). The concept of "Ba": Building a foundation for knowledge creation. California Management Review, 40(3), 40-54.

Nonaka, I., \& Takeuchi, H. (1991). The knowledge creating company. Harvard Business Review, 69, 96-104.

Nonaka, I., \& Takeuchi, H. (1995). The knowledge-creating company: How Japanese companies create the dynamics of innovation. Oxford: Oxford University Press.

Nguyen, H., \& Walker, E. (2000). A first course in Fuzzy Logic (2nd ed.). Boca Raton: Chapman \& Hall.

Papoutsakis, H. (2006). Integrating IT adoptions with knowledge management projects: Lessons from a case study. Journal of the Knowledge Management Professional Society, 3(20), 8-19.

Pierce, J., Kostova, T., \& Dirks, K. (2003). The state of psychological ownership: Integrating and extending a century of research. Review of General Psychology, 17(1), 84-107.

Polanyi, M. (1966). The tacit dimension. New York: Anchor Day Books.

Polanyi, M. (1969). Knowing and being. Chicago: University of Chicago Press.

Reagans, R., \& McEvilly, B. (2003). Network structure and knowledge transfer: The transfer problem revised. Working paper, Columbia University, New York.

Santoro, M., \& Bierly, P. (2006). Facilitators of knowledge transfer in university industry collaborations: A knowledge-based perspective. IEEE Transactions on Engineering Management, 53(4), 495-507.

Santoro, M., \& Saparito, P. (2006). Self-interest assumption and relational trust in university industry knowledge transfers. IEEE Transactions on Engineering Management, 53(3), 335-347.

Shaw, G., \& Williams, A. (2009). Knowledge transfer and management in tourism organizations: An emerging research agenda. Tourism Management, 30(3), 325-335.

Sinkula, J., Baker, W., \& Noordewier, T. (1997). A framework for market-based organizational learning: Linking values, knowledge, and behavior. Journal of the Academy of Marketing Science, 25(4), 305-318.

Sveiby, K. (1996). Transfer of knowledge and the information processing professions. European Management Journal, 14(4), 379-388.

Szulanski, G. (2003). Sticky knowledge: Barriers to knowing in the firm. London: Sage.

Szulanski, G. (Ed.) (2004). Incumbents' framing: How three established firms responded to the emergence of the internet. Advances in Strategic Management, 21. Greenwich, CT: JAI Press.

Szulanski, G. (Ed.) (2005). Strategy process. Advances in Strategic Management, 22. Greenwich, CT: JAI Press. 
Tippins, M., \& Ravipreet, S. (2003). IT competency and firm performance: Is organizational learning a missing link? Strategic Management Journal, 24(8), 745-761.

Weaver, D. (2006). Sustainable tourism: Theory and practice. Oxford: Elsevier.

Weaver, D., \& Lawton, L. (2006). Tourism management. Birsbane, A.U.: John Wiley \& Sons.

Wheeller, B. (1993). Sustaining the ego. Journal of Sustainable Tourism, 1, 121-129.

Winter, S. (1995). Organizing for continuous improvement. In M. Cohen, \& S. Sproull (Eds.), Organizational learning (pp. 460-483). London: Sage.

Vera, D., \& Crossan, M. (2004). Strategic leadership and organizational learning. The Academy of Management Review, 29(2), 222-240.

Zadeh, L. (1965). Fuzzy sets. Information and Control, 8(3), 338-353.

Zadeh, L. (2002). Toward a perception-based theory of probabilistic reasoning with imprecise probabilities. Journal of Statistical Planning and Inference, 105(1), 233-264.

Zadeh, L. (2006). Generalized theory of uncertainty (GTU)-Principal concepts and ideas. Computational Statistics \& Data Analysis, 51(1), 15-46.

Zahra, S., \& George, G. (2002). Absorptive capacity: A review, reconceptualization, and extension. The Academy of Management Review, 27(2), 185-203. 